\title{
Error Analysis of Present Simple Tense in the Interlanguage of Adult Arab English Language Learners
}

\author{
Muneera Muftah ${ }^{1} \&$ Shameem Rafik-Galea ${ }^{2}$ \\ ${ }^{1}$ Department of English, Faculty of Modern Languages and Communication, Universiti Putra Malaysia, Malaysia \\ ${ }^{2}$ Office of Marketing and Communication, Administration Building, Universiti Putra Malaysia, Malaysia \\ Correspondence: Dr. Muneera Muftah, Department of English, Faculty of Modern Languages and \\ Communication, Universiti Putra Malaysia, 43400 UPM Serdang, Selangor D. E., Malaysia. Tel: 603-8946-8944. \\ E-mail: muneeramuftah@yahoo.com
}

Received: November 16, 2012 Accepted: December 19, 2012 Online Published: January 9, 2013

doi:10.5539/elt.v6n2p146 URL: http://dx.doi.org/10.5539/elt.v6n2p146

\begin{abstract}
The present study analyses errors on present simple tense among adult Arab English language learners. It focuses on the error on $3 \mathrm{sg}-s$ (the third person singular present tense agreement morpheme $-s$ ). The learners are undergraduate adult Arabic speakers learning English as a foreign language. The study gathered data from two types of instruments: a grammaticality judgment task (GJT comprising both grammatical and ungrammatical items and an elicited written production task (EWPT). Both tasks were designed to test the learners' underlying knowledge of present simple tense morphology in the Interlanguage (ILG) of adult Arab English language learners. The GJT comprised 12 grammatically/correctly inflected items, 6 omission items (OI) and 6 wrongly/incorrectly inflected items (WI). The findings suggest that adult Arab English language learners seem to have difficulty mastering the use of the $3 \mathrm{sg}-s$ due to first language (L1) interference. The findings of this study have pedagogical implications for English as a foreign language classroom teaching practice as well as for second language teachers and researchers. The most frequent error types produced by the Learners are omission, phonological similarity, incorrect suffixation and substitution.
\end{abstract}

Keywords: error analysis, inflectional morpheme, grammar in ESL, second language learner, second language teaching

\section{Introduction}

Error in language learning and knowledge of grammar has become one of the most important aspects that indicate development of second language (L2) learners' Interlanguage (ILG) system (Lightbown and Spada, 2006). Corder (1981: 260) has argued that errors are considered to be the features of the learner's utterances which are in one way or another different from those of the native speakers. He further states that the learners of a target language are not aware of their errors and thus are unable to correct these errors themselves. The process by which these errors are encountered, computed and analyzed is called Errors Analysis. Richards (1985, p. 96 cited in Tomlinson, 2011) has contended that Error Analysis includes the study and analysis of the errors made by the learners of a second or a foreign language.

In the EFL (English as a foreign language) context, knowledge of grammar, particularly tense, is considered to be the most crucial and difficult part for non-native learners to master properly. The errors committed by the learners also indicate what the second language learners do not master and what they have internalized of the ILG system. Analyzing the Errors made by the learners is the best way to show the true proficiency level of target language they are learning and acquiring at a particular point of time. It also helps the second language researchers to recognize the students' learning problems as well as the factors triggering it. The teachers, on the other hand, can provide their students with appropriate feedback and can use this information to prepare appropriate teaching materials and to design more effective lesson plans. As for the students/language learners themselves, the analysis is inevitable to language learning improvement. That is to say, analyzing these errors which are considered to be systematic in nature is insightful information for second language teachers, learners, researchers and the classroom teaching practice as well (Corder, 1967, cited in Ellis, 1994). Norris and Ortega (2003, p. 717) have argued that error analysis is "used to elicit, observe and record the language (and language related behavior of second language learners) and to enable the resulting evidence in light of explanatory theories 
of the language acquisition process".

Most of the studies on error analysis focus on errors in grammar and structure. The difference between first language (L1) and second language (L2) grammar is assumed to be the major cause of second language learners' errors. Norrish, 1983; Ellis, 1985; Richards and Platt, 1997 cite in the Ravipim Itiravivong's Research, 2002 tried to classify sources of errors. Among these different sources are overgeneralization, first language (L1) interference, incompleteness (i.e. incomplete application and/or ignorance of grammatical rules and rules restrictions). Such errors are considered to be important tool for both teachers and L2 learners. They can beneficiate form them to know what kind of errors occur and how these errors occur in order to understand the second language (L2) learners' learning problems. This information can also be useful for the teachers to plane for appropriate teaching materials and lessons.

The purpose of this study is to examine the acquisition of English tense specifically the present simple tense as it is considered to be problematic for the adult Arab learning English as a foreign language. This difficulty can be attributed to the differences between the first and the second language(s) (i.e. Arabic and English respectively). The main objective of this study is to analyze students' errors in present simple tense and identify the sources of errors as taken from the grammaticality judgment task and the elicited written production task by adult Arab English language learners as well as to provide some pedagogical implications for the English as a foreign language classroom teaching practice as well for second language teachers and researcher

\section{Linguistic Assumptions}

\subsection{The Present Simple Tense in English}

Verbs in English provide information about whether they are happening in the past, present and future. Hence, in English, tense is marked on all verb forms. A verb with the $3 \mathrm{sg}-s$ as in (1) is always finite (White, 2003, p. 180). According to O'Grady (2006, p. 3), English verbal agreement is normally described as easy, simple, transparent, and straightforward. The following example explicates this:

(1) He reads a lot of books.

Guasti (2002, p. 120) has claimed that finite verbs are generally associated with tense and agreement features. In other words, tense feature of finite clauses are morphologically specified as either past or present tense i.e., finite verbs must be spelled out into features that can capture the difference (Muneera and Wong, 2011). For example, in (2), the present tense feature of the verb is spelled out as the $3 \mathrm{sg}-s$.

(2) Ahmad goes to the cinema every Saturday.

However, a root/bare form of a verb can either be finite or non-finite. Bare forms that express the present tense are finite. The example below shows this point:

(3) They read [+finite, -past, +Agr] a lot of books.

That is to say, when the subject in (3) is replaced by $3 \mathrm{sg}$-subject, as in (4a), using the root of the verb results in ungrammatical sentence $\left.{ }^{*}\right)$. In this case, we need to appropriate verb form, i.e., the finite verb with the affixal or $3 \mathrm{sg}-s$ (4b) (see e.g., Muneera and Wong, 2011).

$$
\begin{aligned}
& \text { a. } \\
& \text { b. She read a lot of books. }
\end{aligned}
$$

\subsection{The Imperfect/Present Tense in Arabic}

There are two main morphological verb forms in Arabic: the perfective and the imperfective (Benmamoun, 2000, p. 24; Aoun et al., 2010, p. 19). The perfective form is associated with the past tense, while the imperfective form is associated with the present tense and infinitive. The imperfective form as argued by Benmamoun (2000) and Aoun et al., (2010) can be associated with different temporal interpretations. The following examples obviously demonstrate that the imperfective form does not morphologically carry any temporal or aspectual information.

(5) ya-ktubu simple present tense

a. $\quad 3$ sm.IMP(erf)-write

'He writes'

b.

$$
\text { sa-ya- ktubu }
$$

future tense

$$
\text { fut-3sm-write }
$$


'He will write'

kaana ya- ktubu past tense (context of auxiliary)

c. be. $3 \mathrm{sm} . \mathrm{P}(\mathrm{erf}) \quad 3 \mathrm{sm}$-write

'He was writing./He used to write.'

qad ya-ktubu past tense (context of modal)

d. probable $3 \mathrm{sm}$-write

'He might write.'

laa ta- ktub negative imperative

e. neg 2sm-write

'Don't write.'

?araada ?an yu-ghani

want. $3 \mathrm{sm}$ to $3 \mathrm{sm}$-sing

non-finite clause

'He wants to sing.'

(Examples taken from Benmamoun, 2000, p. 28-30)

In other words, there is no is no one-to-one correspondence between tenses in Arabic and English. The present tense in Arabic functions to indicate the present progressive as well as the simple present.

$$
\begin{array}{lll}
\text { ya-kra?u } & \text { ?a-TTaalib-u } & \text { ?al-qasidat-a } \\
\text { 3sm.IMP(erf)-read } & \text { the-student-nom } & \text { the-poem-acc }
\end{array}
$$

'The student reads the poem.'

'The student is reading the poem.' (Examples adapted from Benmamoun, 2000, p. 32)

In addition, Verbs in Arabic can agree with subjects in person, number and gender (Benmamoun, 2000). Based on the assumptions that are made by Benmamoun, the affixes (both the suffix and the prefix) that distinguish the imperfective/present tense, as illustrated in (7) are said to correspond to both tense and agreement morphology.

$$
\text { ya-rqus-uu }
$$

b.

\section{IMP(erf)-dance-pm}

'He dances/ is dancing' (Examples adapted from Benmamoun, 2000, p. 60-61)

Table 1 presents the various agreement affixes (prefixes and suffixes) that can be attached to the imperfective/present tense form of the verb in Arabic.

Table 1. Imperfective/present tense form Agreement Affixes in Arabic (prefixes and suffixes)

\begin{tabular}{llc}
\hline Affix & & $\mathrm{V}+$ Affix \\
\hline ?a- & ?a-drus & I study \\
ta- & ta-drus & You study \\
ta-ii & ta-drus-ii & You study \\
ya- & ya-drus & He studies \\
ta- & ta-drus & She studies \\
ta-aa & ta-drus-aa & You study \\
ya-aa & ya-drus-aa & They study \\
na- & na-drus & They study \\
\hline
\end{tabular}

However, the question that has been posed and widely debated by researchers is whether or not this verbal paradigm encodes a true tense system. According to Benmamoun (2000), Arabic, unlike English, lacks overt tense morphemes. He further assumes that tense and agreement are separated in Arabic. That is, the affixes shown in table 1 above are agreement morphemes only. (Benmamoun, 2000, p. 28).

Thus, we can conclude that the affixes (the prefix and the suffix) associated the imperfective form/present tense in Arabic are agreement morphemes only. All other additional information carried by other elements are morphologically attached to or syntactically associated with this form. Benmamoun's (2000, p. 30) suggestion is 
that tense (the present simple tense) is also encoded by an abstract morpheme:

\section{Framework}

The study focuses on the analysis of errors on adult L2 acquisition of present simple tense agreement morphology and the Error Analysis theoretical framework developed by Corder (1967) was put to test. Error Analysis presupposes that learners make major elements in the feedback system of language teaching and learning process (Corder, 1967). In the process of L2 acquisition this temporary and changing linguistic system, i.e. the interlanguage (ILG), has continually been developed by L2 learners who are not yet fully proficient but are approximating the target language (Corder,1981). Their competence developed and should advanced gradually until they attain native/near native-like level and thus at ultimate attainment level they can achieve native-like competence in the target language. In light of the above discussion the selection of Error Analysis theoretical framework is valid and proper in order to identify the types of errors committed by adult Arab English language learners in the acquisition process of English simple present tense morphology. Therefore, this study sets out to:

1. analyze the types of grammatical errors that adult Arab English language learners make in their acquisition of English present simple tense agreement morphology (i.e. $3 \mathrm{sg}-\mathrm{s}$ ).

2. provide a better understanding of the acquisition and the use of English present simple tense agreement morphology (i.e. $3 \mathrm{sg}-\mathrm{s}$ ) by adult Arab English language learners.

3. suggest pedagogical implications for the English as a foreign language classroom teaching practice as well for second language teachers.

\section{Methodology}

\subsection{Participants}

The participants of the study are 240 adult Arabic speakers learning English as a foreign language subdivided into three proficiency groups (advanced (AG), upper-intermediate (UIG) and lower-intermediate (LIG)). The formation of the three groups was based on their performance in the Oxford Placement Test (OPT) (Allan, 1992). Of the 240 Arabic speakers, 66 were classified as AG, 84 as UIG and 90 as LIG in terms of their proficiency levels. From the same groups of learners, 77 undergraduates volunteers (20 AG, 25 UIG and 32 lower LIG) participated in the elicited written production task (EWPT). The participants were undergraduate students in two Yemeni Universities (mostly sophomores and juniors). Their average age was 21.67 years. They spent approximately 9.25 years learning English. However; unfortunately, the learners' contact and use of English outside the classroom is limited and in most cases they have no opportunity to contact or to use English outside the Classroom. Since proficiency levels may vary among the learners, their proficiency in English was assessed independently using the OPT.

\subsection{Instrumentation}

\subsubsection{The Grammaticality Judgment Task (GJT)}

The task consisted of English 24 items displaying grammatical and ungrammatical use of present simple tense and agreement morpheme. The morpheme being examined is the $3 \mathrm{sg}-s$. The test items were divided into three sets of items with the types as follows:

- 12 Grammatically/ Correctly inflected items (GI) (e.g., The mother gives money to the poor.)

- 6 Omission items (OI) (Ungrammatical omission of the $3 \mathrm{sg}-s$ ) (e.g., *The student sit in front of the computer.)

- 6 Ungrammatically /Wrongly Inflected items (WI) (Ungrammatical wrong use of the 3sg $-s$ ) (e.g., * My friends works in the bank.)

The participants were given thirty (30) minutes to answer all the items. They were requested to tick $(\sqrt{ })$ when the test item is grammatical and cross $(\mathrm{X})$ when the test item is ungrammatical. The correct judgement of either a grammatical or ungrammatical item is given a score of 1 while the incorrect judgement of these items is given a score of 0 . Statistical tests were run on the learners' scores.

\subsubsection{The Elicited Written Production Task (EWPT)}

The EWPT consisted of two passages and a total of 40 test items covered the use of the $3 \mathrm{sg}-s$. The purpose of having the above constructions was to examine the extent to which adult Arab English language learners can produce the $3 \mathrm{sg}-s$ and to determine the different types of errors that second language learners make in their acquisition of English third person singular present tense agreement morpheme $-s$. The EWPT was administered 
on a whole class basis. The participants were requested to read the passage first then they had to decide the appropriate tense and morphemes to fill in the blanks. The test took about 30 minutes to complete. A correct answer was given a score of 1 while an incorrect answer was given a score of 0 . Statistical tests were run on the learners' scores.

\section{Results}

\subsection{The Grammaticality Judgment Task (GJT)}

Table 2. Mean Percentages of Correct Judgments of All Item Types in the GJT

\begin{tabular}{lllll}
\hline Item type & \multicolumn{3}{l}{ Proficiency Group } & \\
\cline { 2 - 4 } & $\mathrm{AG}$ & $\mathrm{UIG}$ & $\mathrm{LIG}$ & $(\%)$ \\
& $\mathrm{N}=66$ & $\mathrm{~N}=84$ & $\mathrm{~N}=90$ & \\
\hline GI (grammatically inflected items) & $93.33 \%$ & $84.58 \%$ & $69.17 \%$ & $82.36 \%$ \\
OI (omission items) & $89.17 \%$ & $71.67 \%$ & $57.50 \%$ & $72.78 \%$ \\
WI (wrongly inflected items) & $85.00 \%$ & $70.83 \%$ & $46.67 \%$ & $67.50 \%$ \\
\hline
\end{tabular}

$\mathrm{AG}=$ advanced group; $\mathrm{UIG}=$ upper-intermediate group; $\mathrm{LIG}=$ lower-intermediate group

The data in Table 2 shows that the advanced and the upper-intermediate groups performed at native/near native-like level for grammatically inflected items $(93.33 \%$ and $84.58 \%$ respectively). The results of the lower-intermediate indicated that they have stabilized at levels below 80\% (69.17\%), an accepted cut off point for native/near-native like level of acquisition (see e.g., Muneera and Wong, 2011). A one-way ANOVA revealed a significant difference among the three groups of learners $(F(2,237)=15.450, P=.0001)$. Post-hoc Scheffe tests indicate that there are significant differences $(p<.05)$ between the accuracy scores of the lower-intermediate group on the one hand and that of the advanced and the upper-intermediate groups on the other, which suggests that these items have not been acquired satisfactorily by the lower-intermediate group. On the other hand, no significant differences $(p>.05)$ can be detected between the advanced and the upper-intermediate groups in these items. The results, thus, seemed to show that target tense and agreement morpheme (i.e. $3 \mathrm{sg}-s$ ) has been acquired and that the adult Arab English language learners have achieved native-like competence

The output has also shown that the advanced learners seemed to have stabilized at $89.17 \%$ in their correct judgments of the ungrammatical omission (OI) of the $3 \mathrm{sg}-s$. They have rejected items such as *he drive his kids to tennis practice every day. Their ability to judge the ungrammatical omission of the $3 \mathrm{sg}-s$ as ungrammatical indicated that it has been acquired and that the adult Arabic speakers learning English as a foreign language at ultimate attainment have achieved native/near native-like competence. Turning to the performance of the upper-intermediate learners, it was observed that their accuracy in judging the ungrammatical omission of the $3 \mathrm{sg}-s$ was consistently below $80 \%$, a level generally considered to be less than native/near native-like level $(71.67 \%)$. As for the lower-intermediate learners, their performance on these items was the worst $(57.50 \%)$. The failure of the intermediate learners to adequately reject the ungrammatical items where $3 \mathrm{sg}-S$ was omitted shows that Arab English language learners are still indeterminate in their judgments and intuition. A one-way ANOVA revealed a significant difference among the three groups of learners $(F(2,237)=20.334, \mathrm{p}=.0001)$. In addition, Post-hoc Scheffe tests indicated significant differences among the three groups of learners $(p<.05)$.

\subsection{The Elicited Written Production Task (EWPT)}

Table 3. Mean Percentages of Correct Use of 3sg $-s$ in Obligatory Contexts in the Elicited Written Production Task (EWPT)

\begin{tabular}{|c|c|c|c|c|}
\hline \multirow[t]{2}{*}{ Item type } & \multicolumn{3}{|c|}{ Proficiency Group } & \multirow{2}{*}{$(\%)$} \\
\hline & $\begin{array}{c}\mathrm{AG} \\
\mathrm{N}=20\end{array}$ & $\begin{array}{r}\mathrm{UIG} \\
\mathrm{N}=25\end{array}$ & $\begin{array}{l}\mathrm{LIG} \\
\mathrm{N}=32\end{array}$ & \\
\hline GI (grammatically inflected items) & $\begin{array}{l}47 / 60 \\
78.33 \%\end{array}$ & $\begin{array}{l}45 / 75 \\
60.00 \%\end{array}$ & $\begin{array}{l}21 / 96 \\
21.88 \%\end{array}$ & $\begin{array}{l}113 / 231 \\
48.92 \%\end{array}$ \\
\hline OI (omission items) & $\begin{array}{l}4 / 60 \\
6.67 \%\end{array}$ & $\begin{array}{l}6 / 75 \\
8.00 \%\end{array}$ & $\begin{array}{l}17 / 96 \\
17.71 \%\end{array}$ & $\begin{array}{l}27 / 231 \\
11.69 \%\end{array}$ \\
\hline WI (wrongly inflected items) & $\begin{array}{l}9 / 60 \\
15.00 \%\end{array}$ & $\begin{array}{l}24 / 75 \\
32.00 \%\end{array}$ & $\begin{array}{l}58 / 96 \\
60.42 \%\end{array}$ & $\begin{array}{l}91 / 231 \\
39.40 \%\end{array}$ \\
\hline
\end{tabular}

$\mathrm{AG}=$ advanced group; $\mathrm{UIG}=$ upper-intermediate group; $\mathrm{LIG}=$ lower-intermediate group 
The accuracy scores showed that the advanced learners performed slightly higher $(78.33 \%)$ than the upper-intermediate learners $(60.00 \%)$ in the correct use of the $3 \mathrm{sg}$-s. In contrast, the lower-intermediate learners performed the worst in the task (21.88). Overall results a steady improvement with increase in proficiency level was observed. A one-way ANOVA illustrated significant differences among the groups of learners with respect to the correct use of GI 3sg $-s(F(2,74)=34.902, p=.0001)$. Post-hoc Scheffe testes, on the other hand, indicated that the differences between the accuracy scores of the lower-intermediate group on the one hand and that of the advanced and the upper-intermediate groups on the other were significant $(p<.05)$. On the other hand, the accuracy scores of the advanced and the upper-intermediate groups showed no significant differences $(p>.05)$.

The findings above pointed out that the level of morpheme omission was slightly higher for both the upper-intermediate and the lower-intermediate groups $(8.00 \%$ and $17.71 \%$ respectively) than for the advanced group $(6.67 \%)$. Some instances of the omission of $3 \mathrm{sg}-s$ found in the EWPT are given below:

i. Omission of the non-past *He complain(s) that I am too slow (taken from AG 13)

third person singular

agreement morpheme $-s$

*Tam speak(s) English very well (taken from UIG 8)

*Every time Tam says a new word, Liam try(ies) to repeat it (taken from LIG 23)

A one-way ANOVA demonstrated no significant difference across all groups $(F(2,74)=2.407, P=.097)$. In addition, Post-hoc Scheffe tests showed no significant differences $(p>.05)$ across the three groups' performance with respect to the omission of $3 \mathrm{sg}-s$.

As shown in Table 3, it is clear that the percentages of errors including the inappropriate use of 3sg $-s(39.40 \%)$ are higher than that of the ungrammatical omission (11.69\%). The lower-intermediate learners seemed to make more errors $(60.42 \%$ for the inappropriate use of $3 \mathrm{sg}-s$ and $17.71 \%$ for the omission of $3 \mathrm{sg}-s)$. A one-way ANOVA showed a significant difference among all groups $(F(2,74)=17.292, p=.0001)$ Post-hoc Scheffe tests on the wrong use of $3 \mathrm{sg}-s$ indicated significant differences among the groups of learners $(p<.05)$ except between the advanced and the upper-intermediate learners.

The overt realizations of $3 \mathrm{sg}-s$ morpheme seemed to be problematic for the Arab English language learners, especially for the lower-intermediate learners who exhibited the highest percentages in the wrong use of this morpheme. Even at a higher level of proficiency, the overt realizations of the $3 \mathrm{sg}-s$ morpheme seemed to be slightly problematic. This seems to be due to the tense system in English being different from that of Arabic (learners' L1). The errors identified in the use of $3 \mathrm{sg}-s$ morpheme were classified into different subcategories:

a) Errors in the use of $3 \mathrm{sg}-s$ morpheme including phonological similarity, incorrect suffixation (suffixation of -ing and suffixation of the past tense morpheme -ed) and substitution (non- past progressive form and past progressive form instead of simple non-past tense).

*Every time Tam says a new word, Liam trys to repeat it (taken from AG

i. Phonological similarity

16)

*Every time Tam says a new word, Liam tryes to repeat it (taken from LIG 11)

The error identified in this category was the use of inappropriate orthographical forms although there is phonological similarity which was a result of the production of phonologically similar verbs with the correct tense (in this case the present simple tense) but which are different in spelling. The examples above show that although the L2 learners have acquired the underlying syntactic structure, they however, have failed to acquire the overt morphological realization (i.e. $3 \mathrm{sg}-s$ ). As a result they have failed to spell it out and they tend to overgeneralize the use of the simple present tense agreement morpheme. This is due to incomplete learning of the orthograpghy. The L2 learners have generalized the use of the $3 \mathrm{sg}-s$ to all present simple tense verbs with the third person singular subjects, with no exception.

ii. Suffixation of -ing

(V+ing)

iii. Substitution

(Non- past progressive form instead of simple non-past
*Every time Tam says a new word, Liam trying to repeat it (taken from UIG 5)

*Tam speaking English very well (taken from LIG 22)

*Every time Tam says a new word, Liam is trying to repeat it (taken from AG 1)

* He always walks ahead of me and is complaining that I am too slow 
tense)

(taken from LIG 13)

The above errors (a ii and a iii) were a direct translation from Arabic (the learners'L1). Thus, tense errors here can be explained in terms of L1 influence. Another possible explanation for these errors is that although the L2 learners have not yet properly mastered the overt realization of tense morphemes which seemed to be problematic for them.
iv. Substitution
(past progressive tense instead of simple non-past tense)

*Tam was speaking English very well (taken from LIG 15)
v. Suffixation of the past tense *Every time Tam says a new word, Liam tried/tryed to repeat it agreement morpheme -ed (taken from UIG 18)

* He always walks ahead of me and complained that I am too slow (taken from LIG 7)

Again, it seems that the error in (a iv) is the result of incomplete mastery of the English present tense verb system. In addition, the error recognized in (v) indicated that L2 learners have over applied other suffixations that they had already acquired in their ILG grammar showing incomplete application and/or ignorance of grammatical rules and rules restrictions.

\section{Discussion and Conclusion}

In conclusion, the adult Arab English language learners made most of the errors in the written task. The most frequent error types produced by the learners are omission, phonological similarity, incorrect suffixation and substitution. Overall, the results of the study showed that adult Arab ESL learners, particularly the upper-intermediate and the lower-intermediate groups, still have problem mastering the present simple tense and distinguishing it from other tenses efficiently. The Arab English language learners were indeterminate in their intuition although they studied English for almost 7 years before entering the university. They are quite unable to apply what they have learnt properly. They made errors in present simple tense, especially, when present simple tense is used in writing. Accordingly, some of the activities for helping reduce and correct those errors for students/L2 learners who are not yet fully proficient were suggested

\subsection{Suggestions for Teaching Present Simple Tense in English}

Harmer (1998) suggested one of the important activities that should be applied in the class. He asserted on the presentation of the grammar rule or structures in class so that students can see how the particulars are formed in English. Such structures can be either written on the board or visually shown on cards.

In the present study, the grammatical property under investigation is the present simple tense. Thus, some suggestions that highlight on this language area are presented here to help teachers as well as students for reducing this error type:

- Teachers should highlight that verbs in the present simple tense form must take the present tense agreement morpheme $-S$ "V $+-s$ " if the subject is third person singular.

- Teachers should teach their students first what subject can a sentence take (i.e. First, second or third person) an explain that only third person singular subjects can take the $3 \mathrm{sg}-s$ and then teach them both regular and irregular verb forms.

- $\quad$ Teachers should encourage the students to prepare a list including verbs that take the suffix $-s$ or $-e s$ and other verb forms that include a phonological changes to the verb forms such as try (i.e. tries) etc.

The most frequent errors that occurred in this study were omission, misspelling and Substitution of a different tense and verb forms. Teachers should try to reduce these errors by doing the following;

- Students must be encouraged to list the verb forms of the present simple tense with third person singular subjects $(-s$, -es or other verb forms) and another list consisting the same verb forms of the present simple tense with first and second person singular subjects.

- $\quad$ Students must be encouraged to apply the drill practice (Larsen-Freeman, 1986) in learning the present simple tense in English. They first are advised to list the adverbs of time in present simple tense (e.g. always, often, sometimes, etc.) in their notebooks or to draw a chart in order to remind them whenever they are not confident in writing words as learning a new language is a process of habit formation. In other words, students could learn language through repetition and drill practicing is an activity which is very useful for them. 
- After memorizing the adverbs of time in present simple tense and the problematic words, the students should have given more chances to practice writing. This is due to the fact that the students might easily forget the words and the structures if they have few chances to write them. According to Madsen (1983:112-113), dictation is considered to be one of the easiest methods for practice and testing. Thus, dictation might be a useful writing exercise for the students. Dictation may be done during class session, either at the beginning of the class or at the end, for both of individual words and/or of sentences in context.

- Teaching "subject and verb agreement" is another area that teachers should give emphasis to. Not only concentrating on the pronoun subjects but also subjects in other different forms such as noun phrase, noun clause, and noun with adjective clause should also be taught as well.

Most importantly, Teachers and language instructors should also teach grammatical rules through context. After teaching the particular rule with regard to the present simple tense, the student should apply and practice that particular grammatical rule in a context. The teachers may follow these steps:

- $\quad$ Teachers may start by giving their students a multiple choice exercise or a story with some deleted words related to the error types in present simple tense such as adverb of time, subject and verb agreement. Next, the students have to answer by either choosing the appropriate verb forms or adding the correct verbs according to the subjects and tense.

- Teacher may organize the students into small groups of approximately 4-5 students each. The students may then be given a passage, a story or a paragraph where possible errors including omission of agreement suffixes, misspelling errors, substitution of other tenses or verb forms, etc are underlined. The students should learn how to work as a team. Firstly, they should read and discuss them in their groups. Secondly, they should give explanation why the underlined words are wrong. Then, they should try to correct those errors.

In conclusion, we suggest that the first language (L1) interference in writing is problematic for adult Arab learning English as a foreign language. The source of errors may come from lack of communicative language teaching or lack of enough practice of present simple tense. The finding of the present study could provide useful insights to language teachers who teach present simple tense in English grammar course at every level in the way that the teachers could become more aware of present simple tense, especially when this tense is used for writing. English teachers would concentrate on the problematic area of present simple tense teaching. As a result, the teachers and the English language researchers would be able to work hand in hand in improving the present simple tense learning which could be successful for Arab English language learners as this is one of the important elements that could lead to successful language learning.

However, it can be said that the findings from this study may not be conclusive. After all it is hard to say that the most serious problem for non native English speakers is the use of the present simple tense in writing because of the low opportunity for using English in their environment. We hope that the results of this research would be useful for English teachers a well as the Arab learners. This study may also be useful for English teachers as it highlights the Arab English language learners' errors in terms of simple present tense and thus providing an additional teaching material through which they can get more information and understanding of the students' most problematic errors. Other researchers could also be motivated to research the same topic in the future. The findings would also be helpful for other L2 learners who are interested in learning English to understand the problems and difficulties especially in learning English tenses.

\section{Reference}

Allan, D. (1992). The Oxford Placement Test. Oxford: Oxford University Press.

Aoun, E. J., Benmamoun, E., \& Choueiri, L. (2010). The Syntax of Arabic. Cambridge: Cambridge University Press.

Benmamoun, E. (2000). The feature structure of functional categories: a comparative study of Arabic dialects. New York/Oxford, UK: Oxford University Press.

Corder, S. P. (1967). The Significance of learners' errors. International Review of Applied Linguistics, 5(2-3), 161-169.

Corder, S. P. (1981). Error Analysis and Interlanguage. Oxford. Oxford University Press.

Ellis, R. (1994). The study of second language acquisition. Oxford: Oxford University Press.

Freeman, L. (1986). Techniques and principles in language teaching. Oxford: Oxford University Press.

Guasti, M. T. (2002). Language Acquisition: The Growth of Grammar. Bradford Books. Cambridge, MA: MIT 
Press.

Harmer, J. (1998). How to teach English. Edinburgh: Addison Wesley Longman.

Lightbown, P. M., \& Spada, N. (2006). How languages are learned. Oxford: Oxford University Press.

Madsen, H. S. (1983). Techniques in testing. Oxford University Press.

Muneera Y. A. Muftah, \& Wong Bee Eng. (2011). The Acquisition of English be Auxiliary and Thematic Verb Constructions by Adult Arab ESL Learners. International Journal of English Linguistics, 1(2), 91-105. http://dx.doi.org/10.5539/ijel.v1n2p91

Norris, J., \& Ortega, L. (2003). Defining and measuring SLA. In Doughty, C. J., \& Long, M. C. (Eds), The Handbook of Second Language Acquisition. Malden, MA: Blackwell Publishing. http://dx.doi.org/10.1002/9780470756492.ch21

O'Grady, W. (2006). The Problem of Verbal Inflection in Second Language Acquisition. Invited talk to the Pan-Pacific Association of Applied Linguistics. http://www.ling.hawaii.edu/faculty/ogrady/Verbal_inflection_in_SLA.pdf

Ouhalla, J. (1991). Functional categories and parametric variation. London: Routledge. http://dx.doi.org/10.4324/9780203412015

Tomlinson, B. (Ed.) (2011). Materials development in language teaching ( ${ }^{\text {nd }}$ edition). Cambridge, UK: Cambridge University Press.

Ravipim Itiravivong. (2002). An error analysis of present and past simple tense: Case study of employees at Procter and GambleManufacturing (Thailand). Unpublished master's research paper, Thammasat University, Language Center, Teaching English as a foreign Language.

White, L. (2003). Universal Grammar and Second Language Acquisition: From Initial to Steady State. Cambridge: Cambridge University Press. http://dx.doi.org/10.1017/CBO9780511815065 